Int. J. Dev. Biol. 53: 535-540 (2009)

doi: $10.1387 / \mathrm{ijdb} .092855 \mathrm{bp}$

\title{
Developmental expression and regulation of the chemokine CXCL14 in Xenopus
}

\author{
BYUNG-YONG PARK, CHANG-SOO HONG\#, FARAZ A. SOHAIL\#\# and JEAN-PIERRE SAINT-JEANNET* \\ Department of Animal Biology, School of Veterinary Medicine, University of Pennsylvania, Philadelphia, USA
}

\begin{abstract}
Chemokines are a family of proteins originally identified for their activity promoting the recruitment of leukocytes to inflammatory sites. Recent evidence indicates that chemokines and their receptors may also regulate key developmental processes. In this paper we report the expression and regulation of the chemokine CXCL14 during Xenopus laevis embryogenesis. CXCL14 is first detected in several ectoderm derivatives, the dorsal aspect of the retina, the cement gland and the hatching gland. Later in development, additional domains of expression include the head mesenchyme and the medial ventral aspect of the otic vesicle. CXCL14 expression in the ectoderm is regulated by both Bmp and canonical Wnt signaling. In the hatching gland CXCL14 is co-expressed with the transcription factor Pax3. Using gain of function and knockdown approaches in whole embryos and animal explants we show that Pax 3 is both necessary and sufficient for CXCL14 expression in this domain of the ectoderm.
\end{abstract}

KEY WORDS: CXCL, hatching gland, cement gland, otic vesicle, retina

\section{Introduction}

Chemokines form a family of chemotactic cytokines initially identified by their ability to regulate leukocyte trafficking during inflammatory response. They are classified into four groups, CCL, CXCL, XCL and CX3CL, based on the number and spacing of conserved cysteine $(C)$ residues within their sequence. Chemokines mediate their biological effects through interaction with $\mathrm{G}$ protein-coupled receptors. These receptors are referred as CCR, CXCR, XCR and CX3CR based on the chemokine subclass by which they are activated (Zlotnik and Yoshie, 2000).

Chemokines of the CXCL class are best known for promoting directional cellular migration of leukocytes during inflammation (Zlotnik and Yoshie, 2000). They also affect tumor development by influencing angiogenesis, tumor transformation, growth and invasion (Vandercappellen et al., 2008). The up-regulation of several chemokines and their receptors in the adult brain has been implicated in a number of neurodegenerative diseases, such as multiple sclerosis, Alzheimer's disease and dementia (Cartier et al., 2005). A number of recent reports indicate that chemokines may also regulate directional migration of cells in other contexts besides the inflammatory response, including embryogenesis. For example, in the zebrafish disruption of the chemokine CXCL12 (also knows as SDF-1) or its receptor CXCR4a cause the endoderm to separate from the mesoderm and as a result the endoderm migrates more anteriorly than normal, leading to the duplication of endodermal organs (Nair and Schilling, 2008; Mizoguchi et al., 2008). In the mouse embryonic olfactory system, SDF-1/CXCR4 signaling influences sensory axon extension and the migration of gonadotropin releasing hormone-1 neurons (Toba et al., 2008). Signaling through CXCL12/CXCR4b and CXCL12/CXCR7 controls the migration of primordial germ cells in zebrafish and medaka embryos (Boldajpour et al., 2008; Sasado et al., 2008). CXCR7 function has also been implicated in the proper migration of the zebrafish posterior lateral line primordium (Valentin et al., 2007; Dambly-Chaudiere et al., 2007). In Xenopus embryos SDF1/CXCR4 signaling has been proposed to control the directional movement of mesendodermal cells during gastrulation (Fukui et al., 2007). Altogether these studies highlight the importance of this class of molecules during early embryonic

Abbreviations used in this paper: SDF-1, stromal cell-derived factor-1; Trp-2, Tryosinase related protein-2.

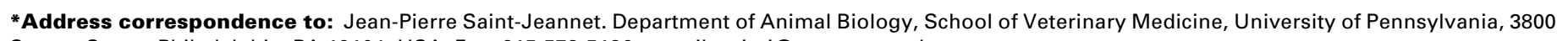
Spruce Street, Philadelphia, PA 19104, USA. Fax: 215-573-5186. e-mail: saintj@vet.upenn.edu

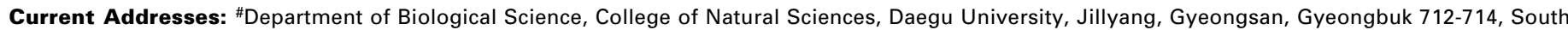
Korea; \#Haverford College, 70 Lancaster Avenue, Haverford, PA 19041, USA. 
development and organogenesis.

We have initiated the characterization of a number of chemokines in the frog Xenopus laevis to analyze the function of this class of molecules during embryogenesis. Here we report the expression of $C X C L 14$ in the embryonic ectoderm and its derivatives and analyze the regulatory inputs that control aspects of CXCL14 expression in this germ layer.

\section{Results \& Discussion}

\section{Sequence and developmental expression of Xenopus CXCL14}

An 1160bp PCR product containing the entire ORF of CXCL14 was amplified from stage 30 cDNA. Sequence analysis (Fig 1A) indicates that at the amino acid level, CXCL14 shares $68 \%$ identity with human CXCL14, also known as BRAK, (Hromas et al., 1999), 67\% identity with mouse CXCL14 (Hromas et al., 1999), 58\% identity with chicken CXCL14 (accession \# NP990043) and 65\% with zebrafish Scyba (Long et al., 2000). Gene synteny analysis (not shown) provides further evidence that the Xenopus gene is the true ortholog of CXCL14.

There is no significant homology between Xenopus CXCL14 and the only other Xenopus CXCL family member isolated to date, SDF-1 (Braun et al., 2002). RT-PCR analysis of the developmental expression of $C X C L 14$ reveals that this chemokine is not maternally expressed in Xenopus. It is first detected at stage 20 and persists throughout development, at least up to stage 40 (Fig 1B). For comparison Xenopus SDF-1 is activated around the same stage (stage 18/20; Braun et al., 2002) while its receptor $C X C R 4$ is maternally expressed and up regulated after the mid-blastula transition (Fukui et al., 2007). CXCL14 is

\section{A}
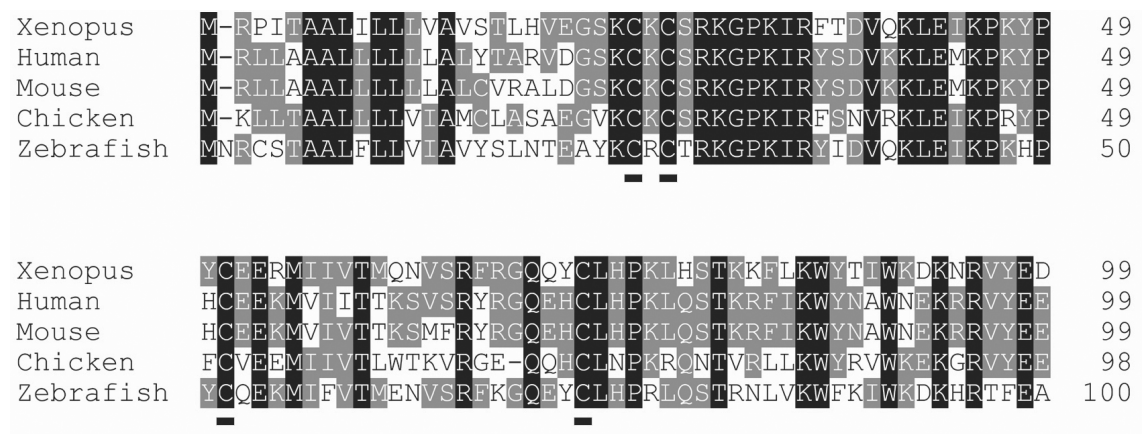

B

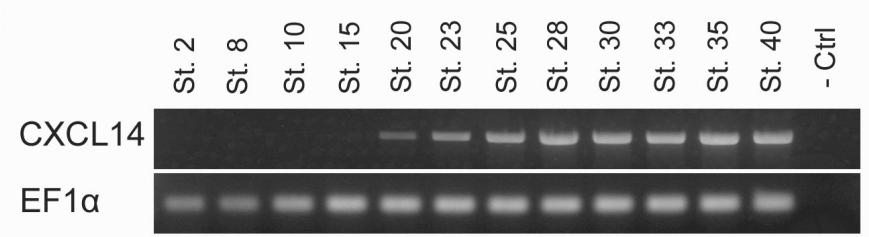

Fig. 1. Sequence and developmental expression of Xenopus CXCL14. (A) Deduced amino acid sequences from human, mouse, chicken and zebrafish CXCL14 were aligned using GeneDoc. Conserved amino acids in all five species or in at least two species are highlighted in black and grey, respectively. The conserved cysteine residues, signature motif of this class of molecules, are underlined. (B) RT-PCR analysis of the developmental expression of CXCL14. Stages are according to Nieuwkoop and Faber (1967). EF1 $\alpha$ is shown as a loading control. among a small number of chemokines with no known receptor.

\section{Spatial expression of Xenopus CXCL14}

To analyze the expression of Xenopus CXCL14, whole-mount in situ hybridization was performed on embryos at different stages. CXCL14 transcripts were first detected at stage 20 in a region anterior to the neural plate corresponding to the prospective cement gland (Fig 2A). By stage 23 CXCL14 is detected in three different domains of the ectoderm the cement gland, the hatching gland and the dorsal anterior part of the optic vesicle (Fig 2B-D). At this stage CXCL 14 expression appears to be restricted to the anterior half of the cement gland (Fig $2 \mathrm{C}$ ). The hatching gland is a specialized group of cells that produces proteolytic enzymes, involved in the digestion of the vitelline envelope and jelly coat (Drysdale and Elinson, 1991). In this tissue CXCL14 is co-expressed with Xhe (Xenopus hatching enzyme; Fig 2E) and the transcription factor Pax3 (Fig 2F). At stage 28, CXCL14 persists in all three domains of the ectoderm and its expression is also initiated in the otic vesicle (Fig 2G-I). CXCL14 is expressed the dorsal portion of the retina, reminiscent to Trp2, a pigment cell-specific enzyme involved in melanin synthesis (Fig 2J; Aoki et al., 2003), suggesting that CXCL14 expression is confined to the pigmented epithelium of the retina. Transverse sections through stage 28 embryos confirm that CXCL14 is indeed conear CXCL 14 expression is restricted to the ventral medial aspect of the otic vesicle (Fig 2M). Later in development (stage 35) CXCL14 expression persists strongly in the pigmented epithelium of the retina dorsally, and the otic vesicle while its expression in the cement gland and the hatching gland starts to fade (Fig $2 \mathrm{~N}$ Q). At this stage CXCL14 is also detected in the head mesenchyme (Fig $2 \mathrm{~N}, \mathrm{O}$ ). In the otic vesicle CXCL14 expression is distinct and medial to that of Otx2, a transcription factor that is confined to the ventral aspect of the otocyst (Saint-Germain et al., 2004; Fig 2R, S). Anatomically the otic expression of CXCL14 overlaps with a region of the otocyst from which the vestibulo-accoustic ganglia derives.

The zebrafish CXCL 14, also known as Scyba, is primarily expressed in the midbrain region and the otic placode at early stages, and later in a subset of hindbrain neurons, the sensory patches of the otic vesicle and the lateral line (Long et al., 2000). While CXCL14 is expressed in derivatives of the ectoderm in both fish and frog, the only common domain of expression of CXCL 14 in both species is the otic vesicle. The divergence in the expression of CXCL14 suggests that the expression pattern and presumably the function of this chemokine may have been altered during evolution. So far the embryonic expression of CXCL14 has not been described in amniotes.

\section{Bmp and canonical Wnt signaling regulate CXCL14 expression in the ectoderm}

Bmp activity alone or in combination with canonical Wnt signaling has been implicated in 

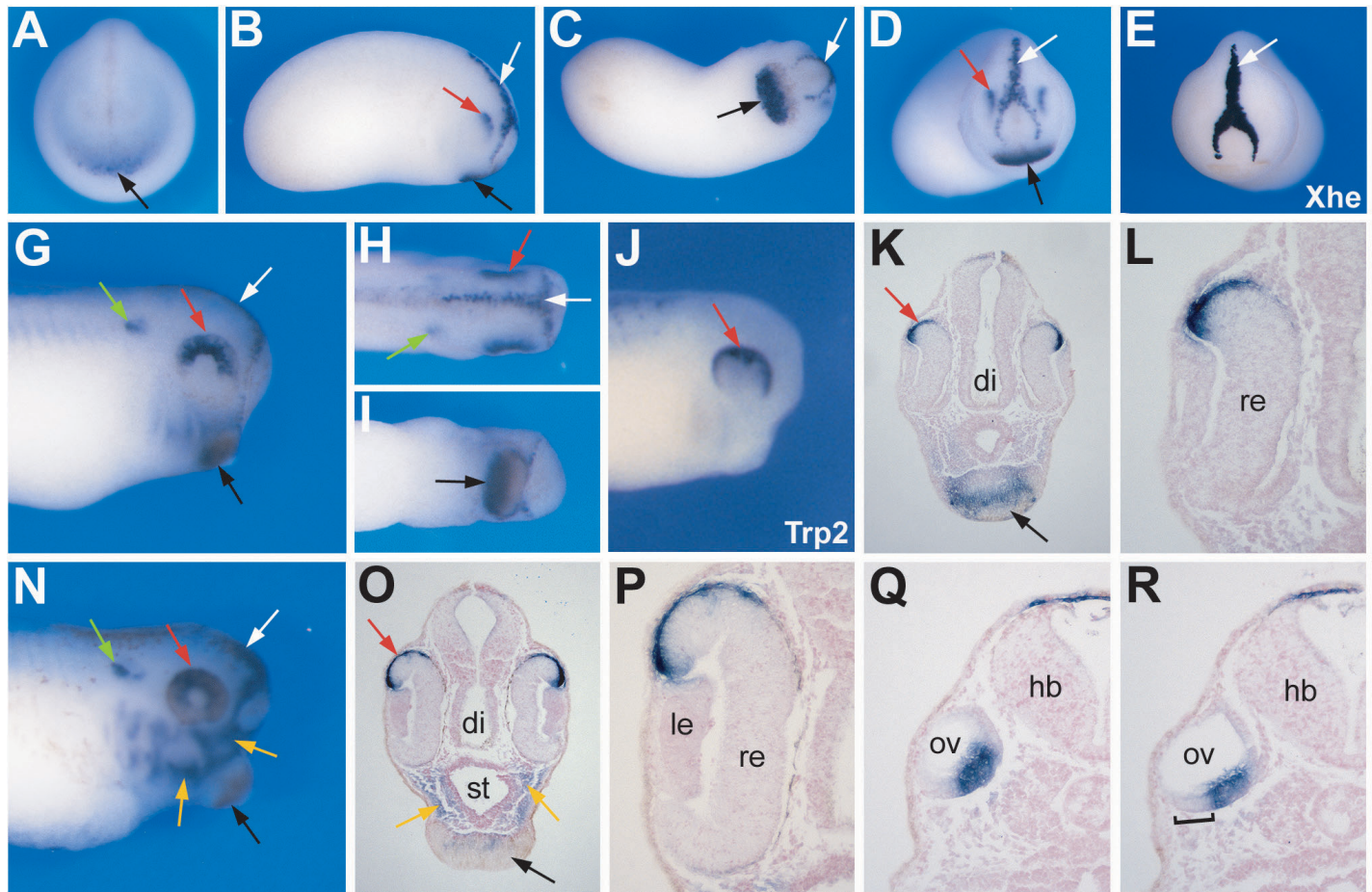
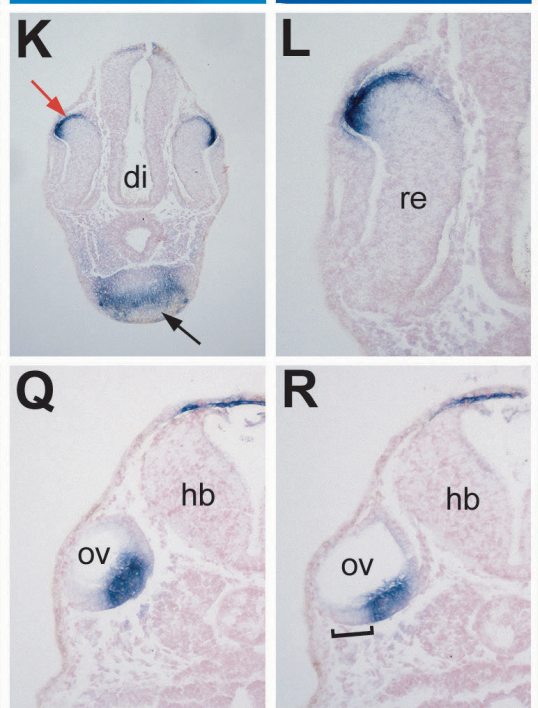

$\mathbf{R}$

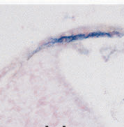

$\mathrm{hb}$
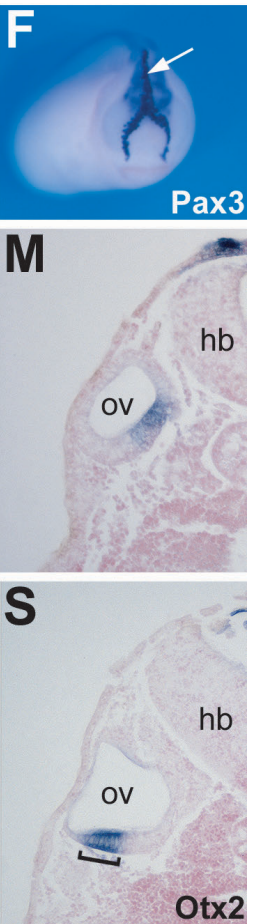

Fig. 2. Expression of CXCL14 by whole-mount in situ hybridization. (A) Onset of CXCL 14 expression at stage 20 in the prospective cement gland anterior to the neural plate (black arrow). Frontal view, dorsal to top. (B-D) At stage 23 CXCL14 is detected in part of the cement gland (black arrows), the dorsal anterior portion of the optic vesicle (red arrows) and the hatching gland (white arrows). (B) Lateral view, dorsal to top, anterior to right. (C) Ventral view, anterior to right. (D) Frontal view, dorsal to top. The expression of Xhe (E) and Pax3 (F) in the hatching gland (white arrows) at this stage are shown for comparison. (E-F) Frontal view, dorsal to top. (G-I) CXCL14 expression at stage 28. In addition to the cement gland (black arrows), optic vesicle (red arrows) and hatching gland (white arrows), CXCL14 is also detected in the otic vesicle (green arrows). (G) Lateral view, dorsal to top, anterior to right. (H) Dorsal view, anterior to right. (I) Ventral view, anterior to right.(J) The expression pattern of Trp2 in the pigmented epithelium of the retina is similar to CXCL14 expression in the developing eye (red arrow). Lateral view, dorsal to top, anterior to right. (K-L) Transverse section highlights the expression of CXCL14 expression in the pigmented epithelium of the retina (red arrow). Panel (L) is a higher magnification view of panel (K). CXCL 14 expression is restricted to the ventral medial aspect of the otic vesicle (M). (N) At stage 35, CXCL14 expression persists in the same domains and is also detected in the head mesenchyme (yellow arrows). Lateral view, dorsal to top, anterior to right. (O-R) Transverse sections showing

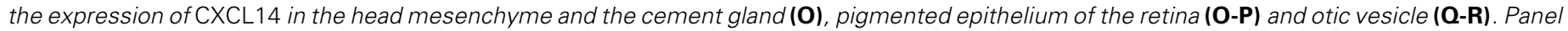
(Q) corresponds to a section posterior to section shown in panel (R). For comparison at this stage Otx2 (bracket) is expressed in the ventral aspect of the otic vesicle (S) a domain that does not overlap with CXCL14 (R). di, diencephalon; hb, hindbrain; le, lens; ov, otic vesicle; re, retina; st, stomodeum.

Fig. 3. CXCL14 expression in the ectoderm is regulated by both Bmp and canonical Wnt signaling. Embryos at the 2-cell stage were injected in the animal pole with two distinct doses of Noggin (N) mRNA (0.4 ng and 1.0 ng) alone or in combination with Wnt1 $(+W)$ mRNA $(0.1 \mathrm{ng})$. Animal explants were dissected at the blastula stage, cultured for 10 hours and analyzed by Real-Time RT-PCR for the activation genes expressed in various domains of the ectoderm. Un, uninjected animal explant. Each value has been normalized to the level of EF- $1 \alpha$ expression.
CXCL14

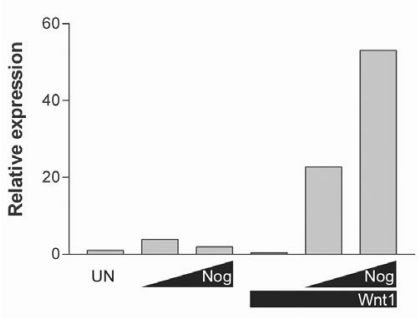

Snail2

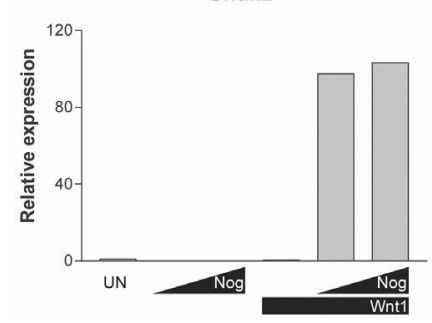

Xhe

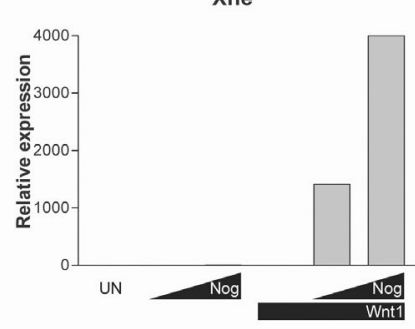

Sox2

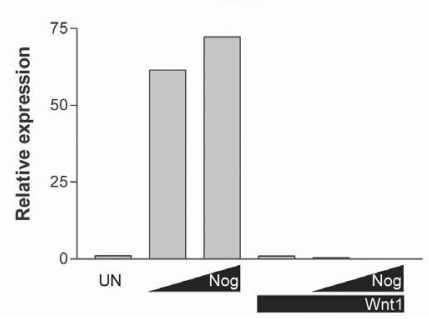

Pax3

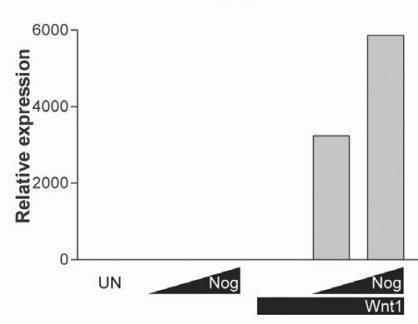

Keratin

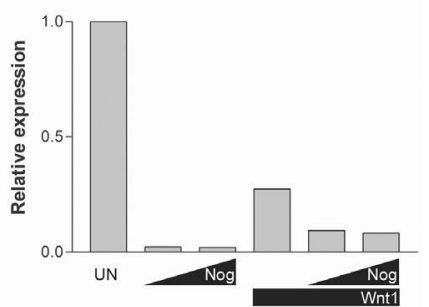



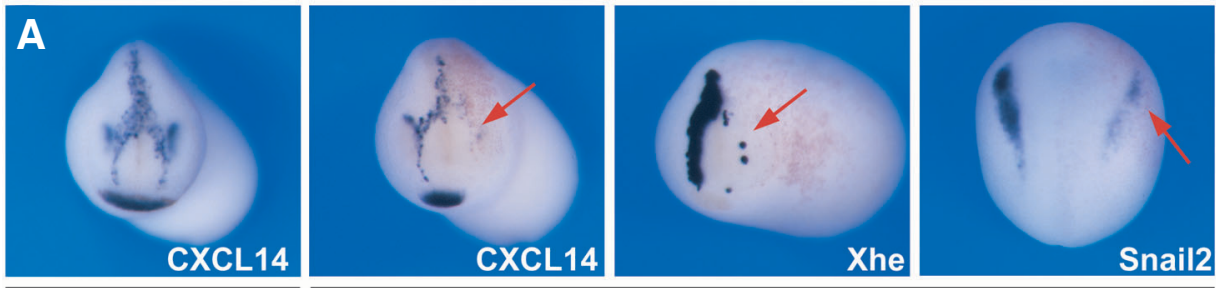

Control
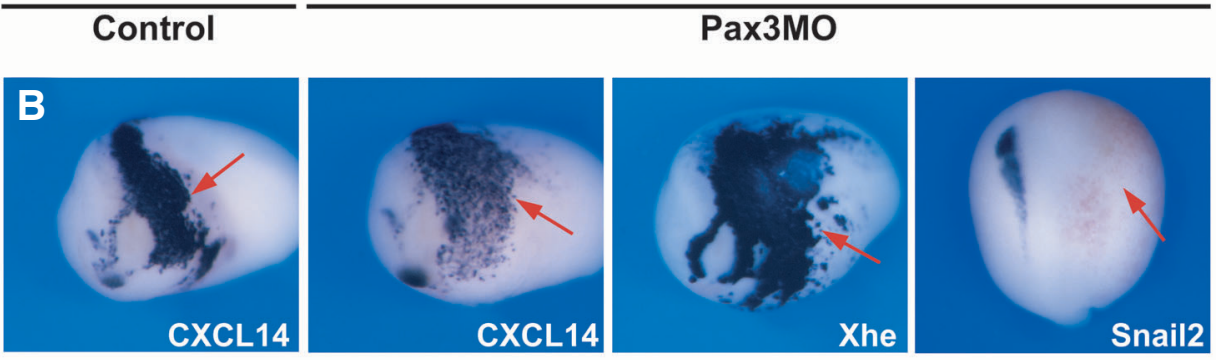

Pax3GR
C

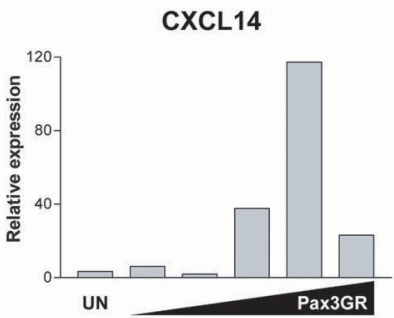

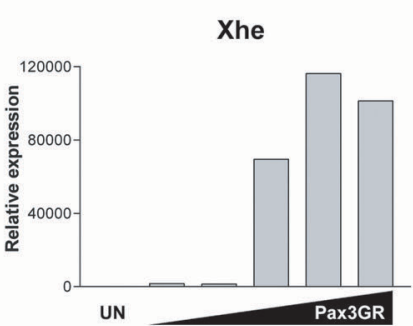

UN

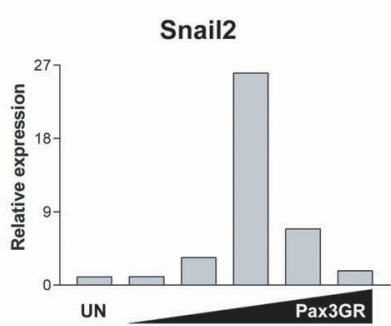

Fig. 4. Pax3 is necessary and sufficient for CXCL14 expression in the hatching gland. (A) Embryos injected with Pax3 morpholino (Pax3MO; 40ng) exhibit a strong reduction of CXCL14 expression in the hatching gland (arrow). In these Pax3-depleted embryos Snail2 and Xhe expression is also reduced at the neurula and tailbud stages, respectively (arrows). (B) Pax3 overexpression $(0.5$ $\mathrm{ng}$ ) in the whole embryo results in a dramatic expansion of CXCL14 and Xhe expression domains at stage 23 (arrows), while Snail2 expression is reduced at stage 15 (arrow). For the embryos hybridized with CXCL14 or Xhe, anterior view is shown, dorsal to top. For Snail2 the embryos are viewed from the dorsal side anterior to top. (C) In animal explants CXCL14 and Xhe are activated by higher doses of Pax3GR mRNA as compared to Snail2. The concentrations of injected Pax3GR mRNA are $0.05 \mathrm{ng}$, $0.1 \mathrm{ng}, 0.25 \mathrm{ng}, 0.5 \mathrm{ng}$ and $1 \mathrm{ng}$. Each Real-Time RT-PCR value has been normalized to the level of EF$1 \alpha$ expression.

the generation of multiple cell lineages in the ectoderm, including the neural crest, the hatching gland, pre-placodal ectoderm, neural plate, cement gland and epidermis (reviewed in Knecht and Bronner-Fraser, 2002; Huang and Saint-Jeannet, 2004). Each one of these cell populations appears to form in response to specific thresholds of Bmp activity (Hong and Saint-Jeannet, 2007). To analyze the regulation of CXCL14 expression in the ectoderm, embryos were injected with two doses of Noggin mRNA alone (to modulate the level of Bmp activity), or in combination with Wnt1 mRNA. The corresponding animal explants were isolated at the blastula stage, cultured for 10 hours (equivalent stage 15) and analyzed by Real-Time RT-PCR. In these explants the expression of CXCL14 was compared to the expression of genes expressed in various domains of the ectoderm, including Pax3 (neural plate border and hatching gland; Bang et al., 1997), Snail2 (neural crest; Mayor et al., 1995), Xhe (hatching gland; Katagiri et al., 1997), Sox2 (neural plate; Mizuseki et al., 1998), and Keratin (epidermis; Jonas et al., 1989).

As previously reported induction of both, neural crest (Snail2) and hatching gland $(X h e)$ fate required Bmp attenuation as well as active Wnt signaling (Saint-Jeannet et al., 1997; LaBonne and Bronner-Fraser, 1998; McGrew et al., 1999). While activation of neural crest- and hatching gland-specific genes occurs in response to the same combination of signals, hatching gland fate requires a higher level of $\mathrm{Bmp}$ inhibition (Fig 3). In this assay CXCL14 follows a pattern of activation similar to that of Xhe and Pax3 (Fig 3; Hong and Saint-Jeannet, 2007), consistent with CXCL14 expression in the developing hatching gland (Fig 2). As expected in these explants the neural plate-specific gene (Sox2) was up regulated by single injection of Noggin mRNA, and associated with strong repression of epidermal fate (Keratin). These results indicate that CXCL14 expression in the ectoderm is largely dependent on the combined activity of Bmp and canonical Wnt signaling.

\section{Pax3 is necessary and sufficient for CXCL14 expression}

Pax3 has been shown to be required for hatching gland formation in Xenopus (Hong and Saint-Jeannet, 2007). To determine whether Pax 3 was also involved in controlling CXCL14 expression is this region of the ectoderm, we used a Pax3specific morpholino oligonucleotide (Pax3MO), which blocks Pax3 translation (Monsoro-Burq et al., 2005). Unilateral injection of Pax3MO at the 2-cell stage inhibited $X$ he $(96 \% ; n=54)$ and Snail2 (100\%; $n=22)$ expression (Fig 4A) as previously reported (Monsoro-Burq et al., 2005; Sato et al., 2005; Hong and Saint-Jeannet, 2007). Pax3 knockdown also prevented CXCL14 expression in the hatching gland (98\%; $n=46$ ) of tailbud stage embryos (Fig $4 A$ ). CXCL14 expression in the cement gland and the dorsal aspect of the retina was also affected in some of these embryos, an effect that is likely to be secondary to the craniofacial defects associated with the loss of neural crest tissue in Pax3 morphants (MonsoroBurq et al., 2005). These results demonstrate that Pax3 is required upstream of $\mathrm{CXCL} 14$ in the developing hatching gland.

We have previously shown that Snail2 induction in the embryo depends on a specific level of Pax 3 activity, and that excess Pax3 activity in the ectoderm is incompatible with neural crest development, but rather promotes hatching gland fate (Hong and SaintJeannet, 2007). We therefore decided to test whether CXCL14 was also dependent on the level of Pax3 activity in the ectoderm. We found that the dose of Pax3GR mRNA ( $0.5 \mathrm{ng}$ ) that induces ectopic Xhe expression (100\% of the embryos; $n=53$ ) and represses Snail2 expression at the neural plate border $(97 \%$ of the embryos; $n=30$ ), also promoted a dramatic expansion of 
CXCL 14 expression domain (Fig 4B) in 100\% of injected embryos $(n=58)$. To confirm these observations we monitored by RealTime RT-PCR the induction of CXCL14 in animal explants derived from embryos injected with increasing doses of Pax3GR mRNA (0.05 ng - $1 \mathrm{ng})$ and cultured in the presence of dexamethasone for 10 hours. As previously described, we found that neural crest (Snail2) and hatching gland (Xhe) fates were specified by different levels of Pax3 activity (Fig 4C; Hong and Saint-Jeannet, 2007). While Snail2 expression is mildly activated by intermediate doses of Pax3GR mRNA (0.25 ng), Xhe is induced by a broader range of Pax3GR mRNA, including the higher dose (1 ng). In these explants the CXCL14 induction profile is more similar to that of $X$ he, with maximum level of induction observed for $0.5 \mathrm{ng}$ of Pax3GR mRNA (Fig 4C).

Altogether these findings indicate that $\mathrm{Pax} 3$ is not only required but is also sufficient for CXCL14 expression in the ectoderm and suggests that its expression in the developing hatching gland depends on specific levels of Pax3 activity.

\section{Materials and Methods}

\section{Isolation of Xenopus CXCL14}

Xenopus CXCL14 was amplified by PCR from stage 30 cDNA using specific primers (F: CGTGGAGCTTGCTCTCTCTT and R: GTGGGCAAGAATGGGTTAAA) based on the sequence available in GenBank (accession \# BC074316). The PCR condition were $94^{\circ} \mathrm{C}(30$ sec.), annealing at $55^{\circ} \mathrm{C}$ (30 sec.), and extension at $72^{\circ} \mathrm{C}$ (90 sec.) for 35 cycles. The resulting 1160 bp PCR product was purified, subcloned into pGEMTeasy (Promega) and sequenced. This construct is referred as pGEMT-CXCL14. The 1160bp PCR product contains the entire ORF of CXCL14 (300 bp), 112bp of 5'UTR and 748 bp of 3'UTR. Gene synteny analysis of human, mouse, chicken, zebrafish and Xenopus CXCL14 was performed using Metazome (http://www.metazome.net).

\section{Xenopus embryo manipulation and injections}

Embryos were staged according to Nieuwkoop and Faber (1967). Wnt1 (0.1 ng; Wolda et al., 1993), noggin (0.4 ng and $1 \mathrm{ng}$; Smith and Harland, 1992) and Pax3GR (0.1 ng - $1 \mathrm{ng}$; Hong and Saint-Jeannet, 2007) mRNAs were synthesized in vitro using the Message Machine kit (Ambion, Austin, TX). Pax3 morpholino antisense oligonucleotide (Pax3MO; 40ng; Monsoro-Burq et al., 2005) was purchased from GeneTools (Philomath, OR). In whole embryo experiments, Pax3GR mRNA and Pax3MO were injected in the animal pole of one blastomere at the two-cell stage and analyzed by in situ hybridization at stage 15 (Snail2) and stage 23 (CXCL14 and Xhe). Embryos injected with Pax3GR were treated with $10 \mu \mathrm{M}$ dexamethasone (Sigma) at stage 11. Sibling injected embryos cultured in the absence of dexamethasone were used as control. For animal explants, both blastomeres of two-cell stage embryos were injected with mRNAs in the animal pole region and animal caps were dissected at the late blastula stage and immediately cultured in vitro in 0.5X NAM (Normal Amphibian Medium; Slack and Forman, 1980). Animal caps from Pax3GR-injected embryos were cultured in 0.5X NAM supplemented with $10 \mu \mathrm{M}$ of dexamethasone. After 10 hours in culture, animal explants were analyzed by Real-Time RT-PCR (Roche Diagnostics) for the expression of various marker genes (Hong and Saint-Jeannet, 2007; Park and Saint-Jeannet, 2008).

\section{Whole-mount in situ hybridization}

In all experiments, blastomeres were co-injected with $1 \mathrm{ng}$ of $\beta$ galactosidase mRNA ( $\beta$-gal, $1 \mathrm{ng}$ ) to identify the injected side. At stage 15 or 23 embryos were fixed in MEMFA (Harland, 1991) and successively processed for Red-Gal (Research Organics) staining and in situ hybridization. Antisense DIG-labeled probes (Genius kit, Roche) were synthe- sized using template cDNA encoding Xhe (Katagiri et al., 1997), Snail2 (Mayor et al., 1995), Trp2 (Aoki et al., 2003), Pax3 (Bang et al., 1997), Otx2 (Pannese et al., 1995) and CXCL14 (pGEMT-CXCL14). Wholemount in situ hybridization was performed as described (Harland, 1991). For histology, stained embryos were embedded into Paraplast+, $12 \mu \mathrm{m}$ sections cut on a rotary microtome and counterstained with Eosin.

\section{Real-time RT-PCR}

For each sample, total RNAs were extracted from 10 animal caps using an RNeasy microRNA isolation kit (QIAGEN, Valencia, CA) according to the manufacturer's direction. During the extraction procedure the samples were treated with DNase I, to eliminate possible contamination by genomic DNA. The amount of RNA isolated from tissues was quantified by measuring the optical density using a spectrophotometer (Beckman Coulter, Fullerton, CA). Real-time RT-PCR was performed using specific primers (Hong and Saint-Jeannet, 2007; Park and Saint-Jeannet, 2008) and the QuantiTect SYBR Green RT-PCR kit (QIAGEN) on a LightCycler (Roche Diagnostics). The primers for CXCL14 were as follow, F: ATGGAAGATGCCAGACAAGG and R: TTCAATGCCAGAATGTTGA. The reaction mixture consisted of $10 \mu \mathrm{l}$ of QuantiTect SYBR Green RTPCR Master Mix, $500 \mathrm{nM}$ forward and reverse primers, $0.2 \mu \mathrm{l}$ of RT, and $60 \mathrm{ng}$ of template RNA in a total volume of $20 \mu \mathrm{l}$. The cycling conditions were as follow: denaturation at $95^{\circ} \mathrm{C}\left(3 \mathrm{sec}\right.$.), annealing at $55^{\circ} \mathrm{C}(4 \mathrm{sec}$.), and extension at $72^{\circ} \mathrm{C}(12 \mathrm{sec}$.). By optimizing primers and reaction conditions, a single specific product was amplified as confirmed by melting curve analysis. Each reaction included a control without template and a standard curve of serial dilutions (in 10-fold increments) of test RNAs. In each case, elongation factor $1 \alpha(E F 1 \alpha)$ was used as an internal reference (data not shown). Each bar on the histograms has been normalized to the level of EF1 $\alpha$.

\section{Acknowledgements}

We are grateful to Dr. Dan Kessler for critical reading of the manuscript. We are also thankful to Drs. Richard Harland, Chris Kintner, Roberto Mayor, Randy Moon and Thomas Sargent for reagents. This work was supported by a grant from the National Institutes of Health (RO1-DC07175).

\section{References}

AOKI, Y., SAINT-GERMAIN, N., GYDA, M., MAGNER-FINK, E., LEE, Y-H., CREDIDIO, C., and SAINT-JEANNET, J-P. (2003). Sox10 regulates the development of neural crest-derived melanocytes in Xenopus. Dev. Biol. 259: 19-33.

BANG, A.G., PAPALOPULU, N., KINTNER, C. and GOULDING, M.D. (1997). Expression of $\mathrm{Pax}-3$ is initiated in the early neural plate by posteriorizing signals produced by the organizer and by posterior non-axial mesoderm. Development 124: $2075-2085$

BOLDAJPOUR, B., MAHABALESHWAR, H., KARDASH, E., REICHMAN-FRIED, M., BALASER, H., MININA, S., WILSON, D., XU, Q. and RAZ, E. (2008). Control of chemokine-guided cell migration by ligand sequestration. Cell 132: 463-473.

BRAUN, M., WUNDERLIN, M., SPIETH, K., KNOCHEL, W., GIERSCHIK, P. and MOEPPS, B. (2002). Xenopus laevis Stromal cell-derived factor 1: conservation of structure and function during vertebrate development, J. Immunol. 168: 2340-2347.

CARTIER, L., HARTLEY, O., DUBOIS-DAUPHIN, M. and KRAUZE, K-H. (2005) Chemokine receptors in the central nervous system: role in brain inflammation and neurodegenerative diseases. Brain Res Rev. 48: 16-42.

DAMBLY-CHAUDIERE C, CUBEDO N. and GHYSEN, A. (2007). Control of cell migration in the development of the posterior lateral line: antagonistic interactions between the chemokine receptors CXCR4 and CXCR7/RDC1. BMC Dev. Biol. 7: 23-37.

DRYSDALE, T.A. and ELINSON, R.P. (1991). Development of the Xenopus laevis hatching gland and its relationship to surface ectoderm patterning. Development 111: 469-478.

FUKUI, A., GOTO, T., KITAMOTO, J., HOMMA, M. and ASASHIMA. M. (2007). 
SDF-1a regulates mesendodermal cell migration during frog gastrulation. Bioch. Bioph. Res. Com. 354: 472-477.

HARLAND, R.M. (1991). In situ hybridization: an improved whole-mount method for Xenopus embryos. Methods Cell Biol. 36: 685-695.

HUANG, X. and SAINT-JEANNET, J-P. (2004). Induction of the neural crest and the opportunities of life on the edge. Dev. Biol. 275: 1-11.

HONG, C-S. and SAINT-JEANNET, J-P. (2007). The activity of Pax3 and Zic1 regulates three distinct cell fates at the neural plate border. Mol. Biol. Cell 18: 2192-2202.

HROMAS, R., BROXMEYER, H.E., KIM, C., NAKSHATRI, H., CHRISTOPHERSON, K., AZAM, M. and HOU, Y.H. (1999). Cloning of BRAK, a novel divergent CXC chemokine preferentially expressed in normal versus malignant cells. Biochem. Biophys. Res. Commun. 255: 703-706.

JONAS, E.A., SNAPE, A.M. and SARGENT, T.D. (1989). Transcriptional regulation of a Xenopus embryonic epidermal keratin gene. Development 106: 399-405.

KATAGIRI, C., MAEDA, R., YAMASHIKA, C., MITA, K., SARGENT, T.D. and YASUMASU, S. (1997). Molecular cloning of Xenopus hatching enzyme and its specific expression in hatching gland cells. Int. J. Dev. Biol. 41: 19-25.

KNECHT, A.K. and BRONNER-FRASER, M. (2002). Induction of the neural crest: a multigene process. Nat. Rev. Genet. 3: 453-461.

LABONNE, C. and BRONNER-FRASER, M. (1998). Neural crest induction in Xenopus: evidence for a two-signal model. Development 125: 2403-2414.

LONG, Q., QUINT, E., LIN, S. and EKKER, M. (2000). The zebrafish scyba gene encodes a novel CXC-type chemokine with distinctive expression patterns in the vestibulo-acoustic system during embryogenesis. Gene Exp. Pattern 97: 183-186.

MAYOR, R., MORGAN, R. and SARGENT, M.G. (1995). Induction of the prospective neural crest of Xenopus. Development 121: 767-777.

MCGREW, L.L., TAKEMARU, K., BATES, R. and MOON, R.T. (1999). Direct regulation of the Xenopus engrailed-2 promoter by the Wnt signaling pathway, and a molecular screen for Wnt-responsive genes, confirm a role for Wnt signaling during neural patterning in Xenopus. Mech. Dev. 87: 21-32.

MIZOGUCHI, T., VERKADE, H., HEATH, J.K., KUROIWA, A. and KIKUCHI, Y. (2008). Sdf1/Cxcr4 signaling controls the dorsal migration of endodermal cells during zebrafish gastrulation. Development 135: 2521-2529.

MIZUSEKI, K., KISHI, M., MATSUI, M., NAKANISHI, S. and SASAI, Y. (1998). Xenopus Zic-related-1 and Sox-2, two factors induced by chordin, have distinct activities in the initiation of neural induction. Development 125: 579-587.

MONSORO-BURQ, A-H., WANG, E. and HARLAND, R. (2005). Msx1 and Pax3 cooperate to mediate FGF8 and WNT signals during Xenopus neural crest induction. Dev. Cell 8: 167-178.

NAIR, S. and SCHILLING, T.F. (2008). Chemokine signaling controls endodermal migration during zebrafish gastrulation. Science 322: 89-92.
NIEUWKOOP, P.D. and FABER, J. (1967). Normal table of Xenopus laevis (Daudin), Amsterdam, The Netherlands: North Holland Publishing Company.

PANNESE, M., POLO, C., ANDREAZZOLI, M., VIGNALI, R., KABLAR, B., BARSACCHI, G. and BONCINELLI, E. (1995). The Xenopus homologue of Otx2 is a maternal homeobox gene that demarcates and specifies anterior body regions. Development 121: 707-720.

PARK, B-Y. and SAINT-JEANNET, J-P. (2008). Hindbrain-derived Wnt and Fgf signals cooperate to specify the otic placode in Xenopus. Dev. Biol. 324: 108121.

SAINT-GERMAIN, N., LEE, Y-H., ZHANG, Y., SARGENT. T.D. and SAINTJEANNET, J-P. (2004). Specification of the otic placode depends on Sox9 function in Xenopus. Development 131: 1755-1763.

SAINT-JEANNET, J-P., HE, X., VARMUS, H.E. and DAWID I.B. (1997). Regulation of dorsal fate in the neuraxis by Wnt-1 and Wnt-3a. Proc. Natl. Acad. Sci. USA 94: 13713-13718.

SASADO, T., YASUOKA, A., ABE, K., MITANI, H., FURUTANI-SEIKI, M., TANAKA, M. and KONDOH, K. (2008). Distinct contributions of CXCR4b and CXCR7/ RDC1 receptor systems in regulation of $P G C$ migration revealed by medaka mutants kazura and yanagi. Dev. Biol. 320: 328-339.

SATO, T., SASAI, N. and SASAI, Y. (2005). Neural crest determination by coactivation of Pax3 and Zic1 genes in Xenopus ectoderm. Development 132: 2355-2363.

SLACK, J.M. and FORMAN, D. (1980). An interaction between dorsal and ventral regions of the marginal zone in early amphibian embryos. J. Embryol. Exp. Morphol. 56: 283-299.

SMITH, W.C. and HARLAND, R.M. (1992). Expression cloning of noggin, a new dorsalizing factor localized to the Spemann organizer in Xenopus. Cell 70: 829840 .

TOBA, Y., TIONG, J.D., MA, Q. and WRAY, S. (2008). CXCR4/SDF-1 system modulates development of $\mathrm{GnRH}-1$ neurons and the olfactory system. Dev. Neur., 68: 487-503

VALENTIN, G., HAAS, P. and GILMOUR, D. (2007). The chemokine SDF1a coordinates tissue migration through the spatially restricted activation of $\mathrm{Cxcr} 7$ and Cxcr4b. Curr. Biol. 17: 1026-1031.

VANDERCAPPELLEN, J., VAN DAMME, J. and STRUYF, S. (2008). The role of CXC cytokines and their receptors in cancer. Cancer Letters 267: 226-244.

WOLDA, S.L., MOODY, C.J. and MOON, R.T. (1993). Overlapping expression of Xwnt-3a and Xwnt-1 in neural tissue of Xenopus laevis embryos. Dev. Biol. 155: 46-57.

WU, J., SAINT-JEANNET, J-P. and KLEIN, P.S. (2003). Wnt-frizzled signaling in neural crest formation. Trends Neurosci. 26: 40-45.

ZLOTNIK, A. and YOSHIE, O. (2000). Chemokines: a new classification system and their role in immunity. Immunity 12: 121-127. 


\section{Further Related Reading, published previously in the Int. J. Dev. Biol.}

See our recent Special Issue Fertilization, in honor of David L. Garbers and edited by Paul M. Wassarman and Victor D. Vacquier at: http://www.ijdb.ehu.es/web/contents. php?vol=52\&issue=5-6

See our recent Special Issue Invasion in Cancer \& Embryonic Development edited by Marc Mareel and Juan Arechaga at: http://www.ijdb.ehu.es/web/contents.php?vol=\&issue=5-6

Stromal-derived factor-1 (SDF-1) expression during early chick development Rizwan Rehimi, Nargis Khalida, Faisal Yusuf, Fangping Dai, Gabriela Morosan-Puopolo and Beate Brand-Saberi

Int. J. Dev. Biol. (2008) 52: 87-92

The countercurrent principle in invasion and metastasis of cancer cells. Recent insights on the roles of chemokines

Ghislain Opdenakker and Jo Van Damme

Int. J. Dev. Biol. (2004) 48: 519-527

The chemokine network in cancer - much more than directing cell movement Hagen Kulbe, Neil R. Levinson, Fran Balkwill and Julia L. Wilson Int. J. Dev. Biol. (2004) 48: 489-496

Expression pattern of BXR suggests a role for benzoate ligand-mediated signalling in hatching gland function.

$L$ A Heath, E A Jones and R W Old

Int. J. Dev. Biol. (2000) 44: 141-144

Molecular cloning of Xenopus hatching enzyme and its specific expression in hatching gland cells.

C Katagiri, R Maeda, C Yamashika, K Mita, T D Sargent and S Yasumasu Int. J. Dev. Biol. (1997) 41: 19-25

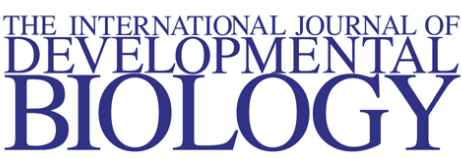

Volume 48 Nos. $5 / 6$

Special issue

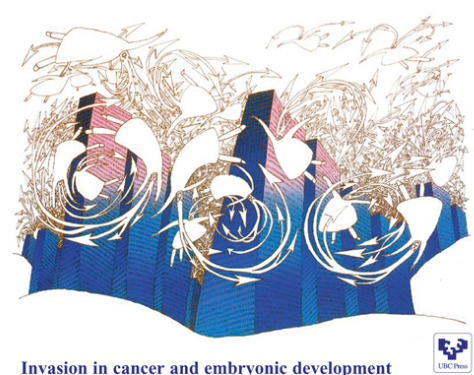

2006 ISI **Impact Factor $=3.577^{* *}$

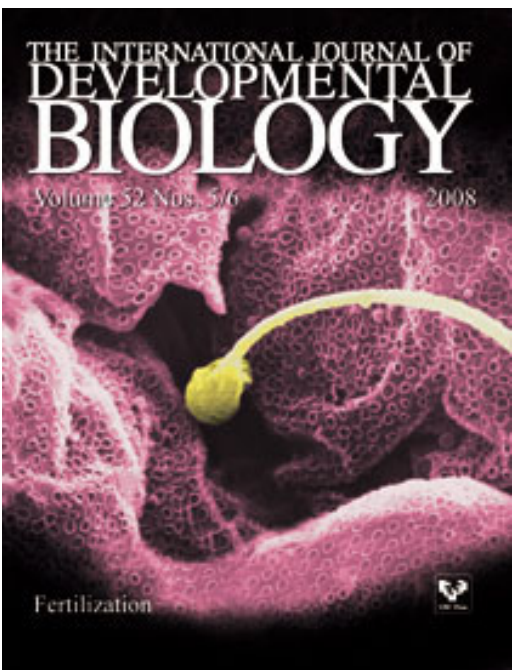

